\title{
Impact of fire on leaf nutrients, arthropod fauna and herbivory of native and exotic eucalypts in Kings Park, Perth, Western Australia
}

\author{
SIPRIANUS RADHO-TOLY, ${ }^{1 \dagger}$ JONATHAN D. MAJER $^{1 \star}$ AND COLIN YATES ${ }^{2}$ \\ ${ }^{1}$ Department of Environmental Biology, Curtin University of Technology, PO Box U1987, Perth, \\ Western Australia 6845, Australia (Email: j.majer@curtin.edu.au) and ${ }^{2}$ Western Australian \\ Herbarium, Department of Conservation and Land Management, Western Australia, Australia
}

\begin{abstract}
The vegetation of Kings Park, near the centre of Perth, Western Australia, once had an overstorey of Eucalyptus marginata (jarrah) or Eucalyptus gomphocephala (tuart), and many trees still remain in the bushland parts of the Park. Avenues and roadsides have been planted with eastern Australian species, including Eucalyptus cladocalyx (sugar gum) and Eucalyptus botryoides (southern mahogany), both of which have become invasive. The present study examined the effect of a recent burn on the level of herbivory on these native and exotic eucalypts. Leaf damage, shoot extension and number of new leaves were measured on tagged shoots of saplings of each tree species in unburnt and burnt areas over an 8-month period. Leaf macronutrient levels were quantified and the number of arthropods on saplings was measured at the end of the recording period by chemical knockdown. Leaf macronutrients were mostly higher in all four species in the burnt area, and this was associated with generally higher numbers of canopy arthropods and greater levels of leaf damage. It is suggested that the pulse of soil nutrients after the fire resulted in more nutrient-rich foliage, which in turn was more palatable to arthropods. The resulting high levels of herbivory possibly led to reduced shoot extension of E. gomphocephala, E. botryoides and, to a lesser extent, E. cladocalyx. This acts as a negative feedback mechanism that lessens the tendency for lush, post-fire regrowth to outcompete other species of plants. There was no consistent difference in the levels of the various types of leaf damage or of arthropods on the native and the exotic eucalypts, suggesting that freedom from herbivory is not contributing to the invasiveness of the two exotic species.
\end{abstract}

Key words: arthropods, Eucalyptus, fire, herbivory, leaf nutrients.

\section{INTRODUCTION}

The Kings Park bushland is a 267-ha remnant of mixed Eucalyptus-Banksia-Allocasuarina woodland, located approximately $1 \mathrm{~km}$ from the Perth Central Business District. The Park was gazetted for public purposes in 1872 and declared an A class reserve in 1900. Today, the bushland is highly disturbed and of the 465 plant species recorded, 290 are native and 175 exotic. Despite this, the Kings Park bushland has significant conservation value and is an important component of the nature reserve system on the Swan Coastal Plain.

It is generally thought that at the time of European settlement, Kings Park was a woodland variously dominated by an overstorey of Eucalyptus gomphocephala (tuart), Eucalyptus marginata (jarrah) and Eucalyptus calophylla (marri). Eucalyptus botryoides (southern mahogany) and Eucalyptus cladocalyx (sugar gum) were

\footnotetext{
${ }^{\star}$ Corresponding author.

†Present address: Department of Biology, University of Nusa Cendana, Kupang, Indonesia.

Accepted for publication April 2001.
}

planted in the Kings Park bushland as part of beautification programs in the 1930 s and used extensively in memorial plantings for fallen soldiers on honour avenues in the 1940s. Eucalyptus botryoides is a small woodland or tall forest tree of coastal areas, and is distributed from approximately Newcastle, New South Wales south to eastern Victoria near Metung (Brooker \& Kleinig 1983). Eucalyptus cladocalyx is a small to tall woodland or forest tree, which is endemic to South Australia and restricted to four disjunct localities on the Eyre Peninsular (Brooker \& Kleinig 1990). Both species have become environmental weeds in Kings Park, recruiting dense cohorts of seedlings following summer wildfires. This increase in abundance has become a serious concern for the conservation of the bushland (Dixon et al. 1995).

The abundances of arthropods on trees are known to be influenced by a range of factors, including the presence of secondary plant compounds (Penfold \& Willis 1961; Hillis 1966; Whittaker \& Feeny 1971) and the toughness of the leaves (Morrow 1983; Ohmart et al. 1987). However, the level of nutrients, particularly nitrogen, within leaves is an important limiting agent 
for the growth and development of phytophagous arthropods (Southwood 1972), and the effect of this could flow through to animals from different trophic levels. In a series of papers concerning arboreal arthropods on native eucalypts within eastern and Western Australian forests, Majer et al. (1992) and Recher et al. (1996) observed that trends in the abundance and diversity of arthropods on the different tree species were consistent with variations in nutrient levels within leaves. Within each of the two forests they studied, tree species with highest foliar nutrient levels supported the greatest abundance and diversity of arthropods. This trend is consistent with the idea that insects respond to higher nutrient levels in foliage (Landsberg 1990; Landsberg et al. 1990).

In view of the fact that eucalypt forests and woodlands experience increases in the availability of soil nutrients following fire (Humphries \& Lambert 1965; Tomkins et al. 1991; Bauhaus et al. 1993; Chambers \& Attiwill 1994), it is possible that increased nutrient uptake by saplings may result in more nutrient-rich foliage. This effect could flow on to arthropod herbivores, with implications for the vigour of the post-fire regrowth.

One reason why E. cladocalyx and E. botryoides are particularly invasive following fire might be that they suffer less herbivory than native eucalypts. As Burdon and Chilvers (1974) and Morrow (1977) have pointed out, this could lead to them exhibiting a greater degree of vigour and competitive ability than the native tree species. Reduced levels of arboreal arthropods on planted exotics in relation to local eucalypt species have already been reported for camphor laurel (Cinnamomum camphora) and tipuana (Tipuana tipu) in Perth (Bhullar \& Majer 2000). This trend is consistent with Southwood's $(1960 ; 1961)$ observation that the more recently the tree species has been present in a country, the fewer herbivorous species it is likely to support. Whether this would be the case for species within the same genus that occur in different environments from either side of a continent is unknown.

The aim of the current investigation was to quantify arthropod levels and degree of herbivory on native and exotic eucalypts within Kings Park in order to see if there was any effect of fire on these factors. We also asked whether differences in the degree of herbivory between native and exotic species contributed to invasiveness of the exotic trees. This is of potential importance in view of the high frequency of fire in the Park and the upsurge of exotic eucalypt seedlings in burnt areas.

\section{METHODS}

The study was carried out in two areas of native bushland in Kings Park. Kings Park is isolated from other native vegetation by urban development to the north and west and by the Swan River to the south and east. Perth has a warm Mediterranean climate, characterized by hot dry summers and mild wet winters. The mean monthly maximum air temperature ranges from $31^{\circ} \mathrm{C}$ in February to $18^{\circ} \mathrm{C}$ in July. Mean annual rainfall is $869 \mathrm{~mm}$, of which $80 \%$ falls in the winter months between May and September. The 'unburnt' area had not been burnt since January 1989, while the 'burnt' area was burnt in January 1996. Both burns were extremely hot, resulting in complete crown scorch of the canopy. Ten 2-4-m high saplings of E. marginata, E. gomphocephala, E. botryoides and E. cladocalyx were selected in July 1998 in both the unburnt and burnt areas. In E. marginata the saplings were resprouts that had grown from lignotubers. In the other three species the saplings grew from seed that germinated in the first winter following the fires. On each sapling, five primary shoots were tagged with a small piece of coloured wire placed basally to the fifth opened leaf down from the apex of the shoot. The distance from the tag to the end of the shoot was measured. The shoots were remeasured at monthly intervals until February 1999, concurrently with counts on the number of new leaves per shoot being taken.

To quantify leaf damage caused by herbivorous insects, the five original leaves on each shoot were scored for area chewed, scraped, mined and galled. Damage in each category was scored on a seven-point scale: $0=$ no damage; $1=<3 \% ; 2=3.1-6 \%$; $3=6.1-12 \% ; 4=12.1-25 \% ; 5=25.1-50 \% ;$ and $6=>50.1 \%$ damage. Recordings were made at monthly intervals through until February 1999.

The fifth leaf back from five randomly selected shoots on the same sapling was removed and placed in a paper bag for subsequent analysis of total nitrogen, potassium and phosphorus levels. All leaves were approximately 2 months old. For the unburnt and burnt areas separately, leaves from the 10 saplings of each species were bulked, dried in an oven at $60^{\circ} \mathrm{C}$ and ground to a fine powder. Samples for the analysis of potassium and phosphorus were digested with perchloric acid, and of nitrogen by Kjeldahl digestion using a Technicon BD-40 digestor. Potassium levels were then measured on a Varian AA 1475 atomic absorption spectrophotometer. Nitrogen and phosphorus levels were analysed after digestion by using a Technicon Autoanalyser II. For nitrogen, a phenolic procedure was used and for phosphorus, the molybdenum blue technique was followed.

In order to quantify arthropod levels on trees, a subset of five nearby saplings of each species in both unburnt and burnt areas was taken. Following clearing of undergrowth, $2 \mathrm{~m} \times 2 \mathrm{~m}$ calico sheets were placed beneath each sapling. Trees were sprayed with $0.3 \%$ pyrethrin $\left(\right.$ Dominex $^{\circledR}$ ) insecticide between 09.00 and 11.00 hours during early May 1999. After allowing $1 \mathrm{~h}$ for the arthropods to die, the saplings were vigorously shaken and the sheets were folded and returned to the 
laboratory. Arthropods were then removed from the sheets for counting and identification at the ordinal level.

All leaf growth, damage and arthropod data were summarized as means and standard errors for each tree species in unburnt and burnt areas. In addition to tabulating damage in the individual categories, values for chewing, mining, scraping and galling categories were combined for each sapling in order to give an overall value for herbivory. The leaf count data were converted to numbers of new leaves per shoot, and shoot extension was calculated by subtracting original shoot measurements from final values on each shoot. For all variables except macronutrients, the mean of the five shoots on each tree was obtained and used as a value for the sapling. As a result of the bulking of leaves, the macronutrient values represented mean values for each tree species, although standard errors could not be calculated.

The study was constrained by the availability of sites in the Kings Park bushland and was therefore limited to a single fire at a single location. Consequently, the saplings that were sampled within the burnt and unburnt areas are not spatially independent and are pseudoreplicates; therefore, strictly speaking, differences between the trees at the two sites cannot be attributed to fire. However, the Kings Park bushland is a relatively homogeneous environment and differences in the soil and vegetation between the burnt and unburnt areas were minimal. Consequently, differences in measured variation are likely to be due to the fire treatment and not localized site effects.

Leaf nutrients were compared between tree species using Kendall's coefficient of concordance (W; Siegel 1956) and between unburnt and burnt areas using a 'sign test' based on the binomial distribution. On the null hypothesis that burning had no effect on leaf nutrients, each macronutrient was assumed to have an equal chance of being at higher or lower levels in the leaves from the burnt area. Leaf growth, leaf damage and arthropod variables were analysed between tree species and fire treatment by two-way analysis of variance (ANOVA) using the SuperANOvA statistical package (Abacus Concepts Inc. 1992). Arthropod counts were transformed by taking the square root in order to stabilize variances. The ANOvA model compared differences between tree species and, within these, between fire treatment. Post-hoc tests were undertaken using Tukey's test with an experimentwise error rate of $5 \%$ in order to determine which differences among observed means for each tree species were significant. A comparison of unburnt and burnt trees of each species was also undertaken using the least squares means method at 0.05 significance.

In order to reduce the number of leaf growth and damage variables that were analysed, the procedure was restricted to the final rather than intermediate recordings. Because ants made up such a large proportion of the total arthropod count and were not generally resident on the tree, the analysis was repeated using total arthropods minus ants. The three most abundant arthropod orders, Araneae, Hemiptera and Coleoptera, were also compared between tree species and fire treatment.

\section{RESULTS}

Taking into account values for macronutrients in leaves from both unburnt and burnt areas, E. marginata generally had the lowest values, followed by E. gomphocephala and then E. cladocalyx; E. botryoides had the most nutrient-rich foliage (Table 1). This ranking was significant $(P<0.01, \mathrm{~W}=0.76)$. In most cases, values for all three macronutrients on each tree species were higher in the burnt than the unburnt areas. The only exceptions were nitrogen, which was lower in E. botryoides leaves from the burnt than unburnt area, and potassium, which was equal in E. cladocalyx leaves from the unburnt and burnt areas. Application of the signs test to data for the four tree species and three macronutrients indicated that the trend of generally higher foliar nutrients in the burnt area was highly significant (10 cases higher in burnt area, one less, one equal; $P<0.05$ using two-tail probability).

Total herbivory levels in the burnt area were significantly higher than those in the unburnt area for all tree

Table 1. Levels of leaf macronutrients ( $\mathrm{mg} \mathrm{g}^{-1} \mathrm{dry}$ weight) in the four tree species within the unburnt (U) and burnt (B) areas of Kings Park during May 1999

\begin{tabular}{lccccc}
\hline Macronutrient & Burnt/unburnt & E. marginata & E. gomphocephala & E. cladocalyx & E. botryoides \\
\hline $\mathrm{N}$ & $\mathrm{U}$ & 0.82 & 1.18 & 1.28 & 1.42 \\
& $\mathrm{~B}$ & 0.93 & 1.24 & 1.31 & 0.05 \\
$\mathrm{P}$ & $\mathrm{U}$ & 0.04 & 0.04 & 0.06 & 0.06 \\
& $\mathrm{~B}$ & 0.06 & 0.07 & 0.60 & 0.07 \\
$\mathrm{~K}$ & $\mathrm{U}$ & 0.40 & 0.56 & 0.60 & 0.61 \\
& $\mathrm{~B}$ & 0.46 & 0.60 & & 0.76 \\
\hline
\end{tabular}

Analyses are based on bulked samples of five leaves taken from each of 10 trees. Although data represent mean values for each tree species, standard errors cannot be calculated (see Methods). 
species except for E. gomphocephala (Table 2). Total herbivory was significantly higher on $E$. marginata and $E$. botryoides than on E. gomphocephala and E. cladocalyx (Table 2). The trends in the different types of leaf damage between tree species were equivocal, with some types of damage significantly higher on one tree species and other types of damage being higher on another (Table 2). This may have resulted from the fact that particular tree species are vulnerable to individual herbivore species. For instance, the high leaf mining score on $E$. marginata resulted from damage by the species-specific jarrah leaf miner, Perthida glyphopa. As a result, inspection of the rankings of tree species in terms of the different types of leaf damage indicated no consistent trend between tree species.

Of greater consistency was the trend in leaf damage levels between unburnt and burnt areas. Although there were no significant differences for chewing in the burnt and unburnt areas, scraping on E. cladocalyx was higher in the burnt area, mining was higher on all tree species except E. gomphocephala in the burnt area, whereas galling was higher on $E$. botryoides in the burnt area (Table 2). The only variable that was significantly higher in the unburnt area was galling on E. gomphocephala.

Eucalyptus gomphocephala produced significantly more leaves per shoot than the other three tree species which, in terms of this variable, did not significantly differ from each other (Table 3). Leaf production was similar in the unburnt and burnt areas on all tree species except for $E$. marginata, which produced more leaves in the burnt area. Shoot extension was significantly higher on $E$. botryoides than on E. cladocalyx, whereas values for $E$. gomphocephala and E. marginata were intermediate between these two species (Table 3). It is noteworthy that shoot extension was significantly lower in the burnt than in the unburnt area for E. gomphocephala and E. botryoides; it was also lower on $E$. cladocalyx, but not significantly so. Shoot extension on unburnt and burnt E. marginata was virtually identical.

Table 2. Mean (standard error) $(n=10)$ for total leaf damage and also leaf damage caused by chewing, scraping, mining and galling on the four tree species in the unburnt (U) and burnt (B) areas of Kings Park during May 1999

\begin{tabular}{|c|c|c|c|c|c|c|c|c|c|}
\hline \multicolumn{2}{|c|}{ Herbivory } & \multicolumn{2}{|c|}{ E. marginata } & \multicolumn{2}{|c|}{ E. gomphocephala } & \multicolumn{2}{|c|}{ E. cladocalyx } & \multicolumn{2}{|c|}{ E. botryoides } \\
\hline \multirow[t]{3}{*}{ Total } & $\mathrm{U}$ & 11.10 & $(1.13)]_{h}$ & 6.60 & $(0.45)]$ & 4.70 & $(0.30)]$ & 7.30 & $(0.56)]_{h}$ \\
\hline & $\mathrm{B}$ & 14.20 & $(1.16)]^{\mathrm{b}}$ & 6.80 & $(0.55)]^{\mathrm{a}}$ & 11.20 & $(1.21)]^{\mathrm{a}}$ & 14.30 & $(1.44)]^{\mathrm{b}}$ \\
\hline & Sig. & $\star$ & & NS & & * & & $\star$ & \\
\hline \multirow[t]{3}{*}{ Chewed } & $\mathrm{U}$ & 5.80 & $(0.42)]_{h}$ & 5.50 & $(0.40)]_{-1}$ & 4.30 & $(0.21)$ & 4.90 & $(0.18)]$ \\
\hline & B & 6.40 & $(0.43)]^{\mathrm{b}}$ & 5.70 & $(0.37)]^{\mathrm{ab}}$ & 5.60 & $(0.79)]^{\mathrm{a}}$ & 4.60 & $(0.48)]^{\mathrm{a}}$ \\
\hline & Sig. & NS & & NS & & NS & & NS & \\
\hline \multirow[t]{3}{*}{ Scraped } & $\mathrm{U}$ & 0.10 & $(0.10)]_{3}$ & 0.10 & $(0.10)]_{a}$ & 0.10 & $(0.10)]_{\mathrm{a}}$ & 1.60 & $(0.50)]_{a}$ \\
\hline & B & 0.10 & $(0.10)]^{\mathrm{a}}$ & 0.10 & $(0.10)]^{\mathrm{a}}$ & 4.7 & $(4.7)]^{\mathrm{a}}$ & 9.60 & $(1.42)]^{\mathrm{a}}$ \\
\hline & Sig. & NS & & NS & & $\star$ & & * & \\
\hline \multirow[t]{3}{*}{ Mined } & $\mathrm{U}$ & 5.20 & $(0.92)]_{h}$ & 0.80 & $(0.29)]$ & 0.10 & $(0.10)]$ & 1.60 & $(0.50)]_{h}$ \\
\hline & $\mathrm{B}$ & 7.70 & $(0.79)]^{\mathrm{b}}$ & 1.00 & $(0.30)]^{\mathrm{a}}$ & 4.7 & $(4.7)]$ & 9.60 & $(1.42)]^{\mathrm{b}}$ \\
\hline & Sig. & $\star$ & & NS & & $\star$ & & $\star$ & \\
\hline \multirow[t]{3}{*}{ Galled } & $\mathrm{U}$ & 0.00 & $(0.00)]_{1}$ & 0.80 & $(0.20)]_{a h}$ & 0.00 & $(0.00)]_{3}$ & 0.20 & $(0.13)]_{h}$ \\
\hline & B & 0.10 & $(1.00)]^{\mathrm{a}}$ & 0.10 & $(0.10)]^{\mathrm{ab}}$ & 0.30 & $(0.21)]^{\mathrm{a}}$ & 2.20 & $(0.84)]^{\mathrm{b}}$ \\
\hline & Sig. & NS & & $\star$ & & NS & & $\star$ & \\
\hline
\end{tabular}

Means are compared by two-way ANOvA. Tree species that share the same letter have mean damage levels that do not significantly differ from each other; Sig. indicates whether means differ between unburnt and burnt treatments (NS, not significant; ^, significant).

Table 3. Mean (standard error) $(n=10)$ number of new leaves per tagged shoot and shoot extension on the four tree species in the unburnt $(\mathrm{U})$ and burnt $(\mathrm{B})$ areas of Kings Park during May 1999

\begin{tabular}{|c|c|c|c|c|c|c|c|c|c|}
\hline \multicolumn{2}{|l|}{ Growth measures } & \multicolumn{2}{|c|}{ E. marginata } & \multicolumn{2}{|c|}{ E. gomphocephala } & \multicolumn{2}{|c|}{ E. cladocalyx } & \multicolumn{2}{|c|}{ E. botryoides } \\
\hline \multirow[t]{3}{*}{ New leaves } & $\mathrm{U}$ & 11.10 & $(1.22)]$ & 29.90 & $(3.86)]_{h}$ & 15.30 & $(1.90)]_{0}$ & 23.10 & $(2.70)]$ \\
\hline & $\mathrm{B}$ & 21.30 & $(2.26)]^{\mathrm{a}}$ & 31.90 & $(5.50)]^{b}$ & 15.60 & $(1.23)]^{\mathrm{a}}$ & 16.50 & $(1.66)]^{\mathrm{a}}$ \\
\hline & Sig. & $\star$ & & NS & & NS & & NS & \\
\hline \multirow[t]{3}{*}{ Shoot extension $(\mathrm{cm})$} & $\mathrm{U}$ & 17.38 & $(2.04)]$ & 24.22 & $(2.26)]_{\mathrm{b}}$ & 16.34 & $(1.82)$ & 25.72 & $(2.10)]$ \\
\hline & B & 17.28 & $(1.76)]^{\mathrm{aO}}$ & 17.32 & $(2.02)]^{\mathrm{D}}$ & 13.50 & $(1.23)]^{\mathrm{a}}$ & 19.60 & (2.09) \\
\hline & Sig. & NS & & $\star$ & & NS & & $\star$ & \\
\hline
\end{tabular}

Tree species that share the same letter have mean values that do not significantly differ from each other; Sig. indicates whether means differ between unburnt and burnt treatments (NS, not significant; ${ }^{\star}$, significant). 
A total of 11 orders were sampled, with spiders (Araneae), sucking bugs (Hemiptera), beetles (Coleoptera) and ants (Formicidae) being the most abundant. Table 4 indicates that total arthropod levels were significantly higher on $E$. gomphocephala, but did not differ significantly between the other three species. The difference between $E$. gomphocephala and the other three tree species was largely accounted for by an abundance of ants. When the analysis was repeated with ants excluded from the total arthropod count, E. gomphocephala still had significantly more arthropods and E. cladocalyx had significantly fewer; levels on the other two tree species were intermediate (Table 4). When ants were excluded from the total count, arthropod levels were significantly higher in the burnt area on all tree species except for E. marginata (Table 4). Levels of the three most abundant orders (excluding ants) were often significantly higher on certain tree species in the burnt than in the unburnt area (i.e. Araneae on E. gomphocephala, Hemiptera on E. gomphocephala and E. botryoides and Coleoptera on E. gomphocephala and E. cladocalyx (Table 4)).

\section{DISCUSSION}

Our findings indicate that leaf macronutrients were mostly higher in all four species in the burnt area and this was associated with generally higher numbers of canopy arthropods and higher levels of leaf damage. Steinbauer et al. (1998) also observed higher foliar nutrient concentrations of nitrogen and a greater abundance of the herbivorous coreid Amorbus obscuricornis on eucalypts that coppiced following wildfire than on non-coppiced plants. There are different mechanisms that may account for the higher levels of macronutrients in post-fire leaves. First, light availability in the burnt environment may have been higher than in the unburnt environment as a consequence of removal or thinning of the canopy by the fire. The increased availability of light in the burnt area may have resulted in an increased investment in photosynthetic capacity and therefore more macronutrients per unit of leaf area (Hirose \& Werger 1987). Second, and probably most likely, the pulse of soil nutrients after the fire resulted in increased nutrient availability and uptake by saplings and also in more nutrient-rich foliage. This nutrient-rich foliage may be more palatable to arthropods, as is the case with plants that are enriched by nutrients from fertilizers or excretions from stock (Landsberg 1990; Landsberg et al. 1990). Enhanced nutritional rewards may have resulted in the elevated levels of arthropods, including hemipterans (herbivores) and beetles (representing herbivores plus some other trophic levels). However, differences in plant architecture between saplings in burnt and unburnt areas that may influence arthropod behaviour (e.g. ovipositing) cannot be ruled out as a factor affecting arthropod abundance (see Steinbauer et al. 1998). The increase in predaceous spiders may have been a cascade effect, of the type discussed by Letourneau and Dyer (1998), resulting from increased arthropod food resources.

The elevated levels of arthropods in the burnt area do not appear to have diminished the production of leaves of three of the tree species. The higher level of leaf production on $E$. marginata, but not of the other three species in the burnt area (Table 3), is of interest because E. marginata is the only species that had sprouted from a lignotuber after the fire; the other three

Table 4. Mean (standard error) $(n=10)$ numbers of total arthropods, total arthropods excluding ants, Araneae (spiders), Hemiptera (sucking bugs) and Coleoptera (beetles) sampled by chemical knockdown of the four tree species in the unburnt and burnt areas of Kings Park during May 1999

\begin{tabular}{|c|c|c|c|c|c|c|c|c|c|}
\hline \multicolumn{2}{|l|}{ Arthropod measures } & \multicolumn{2}{|c|}{ E. marginata } & \multicolumn{2}{|c|}{ E. gomphocephala } & \multicolumn{2}{|c|}{ E. cladocalyx } & \multicolumn{2}{|c|}{ E. botryoides } \\
\hline \multirow[t]{3}{*}{ Total arthropods } & $\mathrm{U}$ & 39.40 & $(10.40)]_{0}$ & 818.40 & $(165.45)]_{h}$ & 5.40 & $(0.75)]$ & 27.00 & $(4.91)]$ \\
\hline & B & 31.40 & $(9.09)]^{\mathrm{a}}$ & 91.40 & $(43.79)]^{\mathrm{b}}$ & 27.40 & $(2.73)]^{\mathrm{a}}$ & 37.40 & $(9.58)]^{\mathrm{a}}$ \\
\hline & Sig. & NS & & $\star$ & & NS & & NS & \\
\hline \multirow{3}{*}{ Total arthropods (excl. ants) } & $\mathrm{U}$ & 11.20 & $(2.08)]_{1}$ & 9.80 & $(3.11)]_{h}$ & 3.20 & $(0.49)]$ & 5.80 & $(0.58)]_{1}$ \\
\hline & $\mathrm{B}$ & 16.00 & $(2.26)]^{a b}$ & 34.60 & $(9.29)]^{b}$ & 18.80 & $(2.71)]^{\mathrm{a}}$ & 22.00 & $(4.88)]^{a b}$ \\
\hline & Sig. & NS & & $\star$ & & $\star$ & & $\star$ & \\
\hline \multirow[t]{3}{*}{ Araneae } & $\mathrm{U}$ & 8.00 & $(1.95)]_{h}$ & 3.60 & $(0.93)]_{h}$ & 1.40 & $(0.68)]$ & 3.00 & $(0.71)]$ \\
\hline & $\mathrm{B}$ & 7.00 & $(1.82)]^{\mathrm{b}}$ & 9.80 & $(3.51)]^{b}$ & 4.00 & $(1.45)]^{6}$ & 7.00 & $(1.58)$ \\
\hline & Sig. & NS & & $\star$ & & NS & & NS & \\
\hline \multirow[t]{3}{*}{ Hemiptera } & $\mathrm{U}$ & 1.20 & $(0.74)]_{3}$ & 1.00 & $(0.45)]_{0}$ & 0.10 & $(0.10)]_{0}$ & 0.60 & $(0.40)]_{0}$ \\
\hline & B & 1.60 & $(0.51)]^{\mathrm{a}}$ & 6.20 & $(1.53)]^{\mathrm{a}}$ & 4.7 & $(4.7)]^{a}$ & 5.60 & $(1.08)]$ \\
\hline & Sig. & NS & & $\star$ & & $\star$ & & $\star$ & \\
\hline \multirow[t]{3}{*}{ Coleoptera } & $\mathrm{U}$ & 1.20 & $(0.74)]$ & 0.20 & $(0.20)]$ & 0.00 & $(0.00)]$ & 0.20 & $(0.13)]_{0}$ \\
\hline & B & 1.00 & $(0.45)]^{\mathrm{a}}$ & 2.40 & $(0.75)]^{\mathrm{a}}$ & 1.20 & $(0.20)]^{\mathrm{a}}$ & 2.20 & $(0.84)]$ \\
\hline & Sig. & NS & & $\star$ & & $\star$ & & $\star$ & \\
\hline
\end{tabular}

Tree species that share the same letter have mean arthropod levels that do not significantly differ from each other; Sig. indicates whether means differ between unburnt and burnt treatments (NS, not significant; *, significant). 
species would have recently grown from seed. Mazanec (1999) has noticed enhanced leaf production on mature E. marginata trees in recently burnt areas and attributed this to reduced competition for water by the understorey, which can be largely burnt out during the fire. It is also possible that, despite elevated levels of herbivory in the burnt area, E. marginata is able to redirect resources stored in the lignotuber in order to produce more foliage. Trees that arise from recent germination of seeds may have less opportunity to utilize water that is deeper in the soil profile or to redirect nutrients from other parts of the plant.

In contrast to leaf production, shoot extension in E. gomphocephala, E. botryoides and possibly E. cladocalyx was reduced in the burnt area. There may be different reasons for this. First, in the post-fire environment the canopy has been removed or thinned, consequently there may be less competition for light and therefore less need for shoots to extend upwards. Second, as the present study has shown, leaves in the post-fire environment contain more nutrients, and there are greater numbers of arthropods and increased rates of herbivory. This may result in reduced shoot growth in saplings that grew up following the fire. If this relationship is causal, there may be a trade off for the plant, which in the nutrient rich post-fire environment can produce nutrient-rich, photosynthetically superior leaves that achieve higher growth rates but are poorly defended against herbivores (Westoby 1998). Alternatively, if reduced shoot extension in the postfire environment is caused by increased abundance in herbivores, it may be an example of a negative feedback mechanism that reduces the vigour of plant growth following fire: increased leaf nutrients result in increased arthropod levels, which in turn lead to increased herbivory. This results in reduced shoot growth on saplings that grew up following the fire and may serve to reduce the plant's ability to compete with other species (Fig. 1). If this is the case, the mechanism does not differentiate between exotic and native species and hence release from herbivory is not a factor contributing to the invasiveness of $E$. cladocalyx or E. botryoides.

The data presented here also indicate that there was no consistent difference in the levels of the various types of leaf damage or of arthropods on the exotic and the native eucalypts. Although we did not identify the arthropods to species level, our impression during sorting was that species richness tracked ordinal richness, suggesting that both groups of trees supported similar

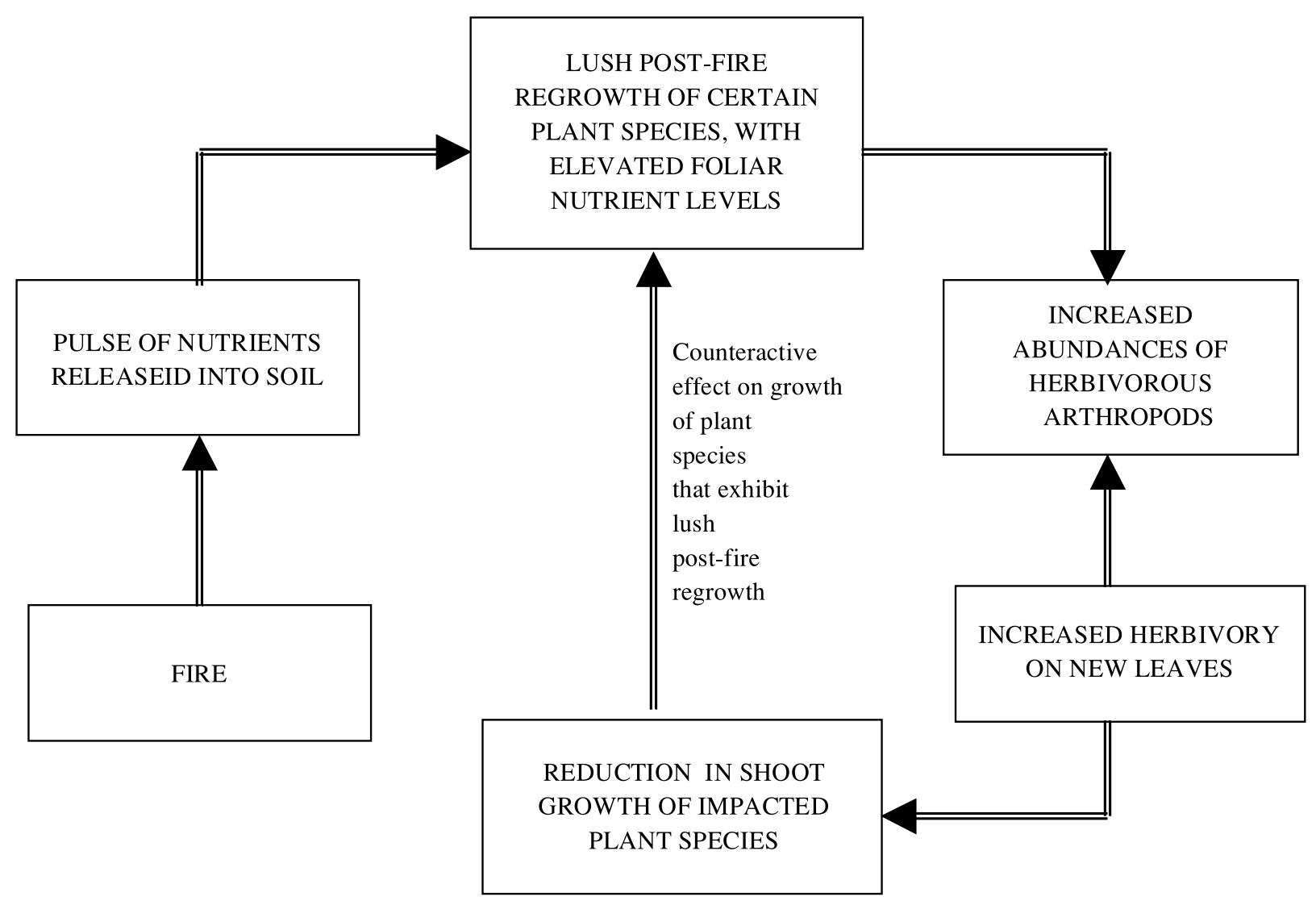

Fig. 1. Schematic diagram illustrating the interaction between fire, soil and leaf nutrients, herbivores and plant vigour during the period following a fire. The negative feedback loop may contribute to maintaining plant species richness. 
varieties of arthropods. The leaves of both exotic species tended to be rich in nutrients when compared with E. marginata and E. gomphocephala (Table 1). Because, as already mentioned, the levels of herbivores on trees can be influenced by the nutritional quality of foliage, there may be a response of arthropods to nutrient levels that offsets the alien nature of these two tree species. Thus, for saplings at least, the native fauna are utilizing the exotic eucalypts and, as a consequence, release from herbivory does not appear to contribute to their invasiveness. However, further research comparing rates of herbivory on the exotic eucalypts in the alien and native habitats is required to absolutely confirm the validity of this conclusion.

It should be stressed that the trends in herbivory and shoot growth that were observed in the present study apply to immature plants, particularly of species that have germinated or resprouted from lignotubers following a fire. At this stage there is no evidence to say that these findings apply to mature trees, which have the ability to redirect resources from other parts of the plant. The impact of burning on herbivores and herbivory of mature trees would be a worthwhile investigation to undertake.

\section{ACKNOWLEDGEMENTS}

We thank Kings Park and Botanic Gardens for allowing us to carry out the work and for providing logistic support. Dr Ian McClean provided valuable advice and Rebecca Graham assisted with the sorting of arthropods. Mercy Radho-Toly provided valuable field assistance. Prof. Byron Lamont, Prof. Harry Recher, Prof. Sharon Strauss, Dr Martin Steinbauer, Dr Christine Stone and two anonymous referees provided valuable comments on an earlier draft of the manuscript.

\section{REFERENCES}

Abacus Concepts Inc. (1992) SuperANOVA. Abacus Concepts Inc., Berkeley, California.

Bauhaus J., Khana P. K. \& Raison R. J. (1993) The effect of fire on carbon and nitrogen mineralisation and nitrification in an Australian forest soil. Aust. F. Soil Res. 31, 621-39.

Bhullar S. \& Majer J. D. (2000) Street trees for wildlife and for people. Pac. Cons. Biol. 6,171-3.

Brooker M. H. \& Kleinig D. A. (1983) Field Guide to Eucalypts: South-Eastern Australia. Inkata Press, Melbourne.

Brooker M. H. \& Kleinig D. A. (1990) Field Guide to Eucalypts: South-Western and Southern Australia. Inkata Press, Melbourne.

Burdon J. J. \& Chilvers G. A. (1974) Fungal and insect parasites contributing to niche differentiation in mixed species stands of eucalypt saplings. Aust. F. Bot. 22, 103-14.

Chambers D. P. \& Attiwill P. M. (1994) The ashbed effect in Eucalyptus regnans forest: Chemical, physical and microbiological changes in soil after heating or partial sterilisation. Aust. F. Bot. 42, 739-49.

Dixon I. R., Keys K., Paynter R., Keighery B., Dixon K. W. \& Hopper S. D. (1995) Kings Park Bushland Management Plan. Kings Park and Botanic Garden, Perth.

Hillis W. E. (1966) Polyphenols in the leaves of Eucalyptus L'Herit: A chemotaxonomic survey. Introduction and a study of the series Globulares. Phytochemistry 5, 1075-90.

Hirose T. \& Werger M. J. A. (1987) Maximizing daily canopy photosynthesis with respect to the leaf nitrogen allocation pattern in the canopy. Oecologia 72, 520-6.

Humphries F. R. \& Lambert M. J. (1965) An examination of a forest site which has exhibited the ashbed effect. Aust. F. Soil Res. 3, 81-94.

Landsberg J. (1990) Dieback of rural eucalypts: Does herbivory relate to dietary quality of tree foliage? Aust. F. Ecol. 15, 72-87.

Landsberg J., Morse J. \& Khanna P. (1990) Tree dieback and insect dynamics in remnants of native woodlands on farms. Proc. Ecol. Soc. Aust. 16, 149-65.

Letourneau D. K. \& Dyer L. A. (1998) Density patterns of Piper ant-plants and associated arthropods: Top-predator trophic cascades in a terrestrial system? Biotropica 30, 162-9.

Majer J. D., Recher H. F. \& Ganeshanandam S. (1992) Variation in foliar nutrients in Eucalyptus trees in eastern and Western Australia. Aust. F. Ecol. 17, 383-93.

Mazanec Z. (1999) The influence of the jarrah leaf miner Perthida glyphopa Common (Lepidoptera; Incurvariidae) and prescribed burning on the girth increment of jarrah Eucalyptus marginata Donn ex Smith. Aust. For. 62, 172-81.

Morrow P. A. (1977) Host specificity of insects in a community of co-dominant Eucalyptus species. Aust. F. Ecol. 2, 89-106.

Morrow P. A. (1983) The role of sclerophyllous leaves in determining insect grazing damage. In: Mediterranean-Type Ecosystems (eds F. J. Kruger, D. T. Mitchell \& J. U. Jarvis) pp. 509-24. Springer-Verlag, Berlin.

Ohmart C. P., Thomas J. R. \& Stewart L. G. (1987) Nitrogen, leaf toughness and the population dynamics of Paropsis atomaria Olivier (Coleoptera: Chrysomelidae): A hypothesis. F. Aust. Entomol. Soc. 26, 203-7.

Penfold A. R. \& Willis J. L. (1961) The Eucalypts. Interscience, New York.

Recher H. F., Majer J. D. \& Ganesh S. (1996) Eucalypts, insects and birds: On the relationship between foliar nutrients and species richness. For. Ecol. Manag. 85, 177-95.

Siegel S. (1956) Nonparametric Statistics for the Behavioural Sciences. McGraw-Hill, New York.

Southwood T. R. E. (1960) The abundance of Hawaian trees and the number of their associated insects. Hawaian Entomol. Soc. 17, 299-303.

Southwood T. R. E. (1961) The number of species of insect associated with various trees. F. Anim. Ecol. 30, 1-3.

Southwood T. R. E. (1972) The insect-plant relationship: an evolutionary perspective. In: Insect-Plant Relationships (ed. H. F. Van Emden) pp. 3-30. Wiley, New York.

Steinbauer M. J., Clarke A. R. \& Paterson S. C. (1998) Changes in eucalypt architecture and the foraging behaviour and development of Amorbus obscuricornis (Hemiptera: Coreidae). Bull. Entomol. Res. 88, 641-51.

Tomkins I. B., Kellas J. D., Tolhurst K. G. \& Oswin D. A. (1991) Effects of fire intensity on soil chemistry in a eucalypt forest. Aust. F. Soil Res. 29, 25-47.

Westoby M. (1998) A leaf-height-seed (LHS) plant ecology strategy scheme. Plant Soil 199, 213-27.

Whittaker R. H. \& Feeny P. P. (1971) Allochemicals: Chemical interactions between species. Science 171, 757-70. 